\title{
New species and records of the pseudoscorpion family Menthidae (Pseudoscorpiones)
}

\author{
Mark S. Harvey \\ Department of Terrestrial Invertebrates, Western Australian Museum, \\ Locked Bag 49, Welshpool DC, Western Australia 6986, Australia
}

\begin{abstract}
New locality records are presented for Menthus rossi (Chamberlin), M. mexicanus Hoff, $M$. californicus Chamberlin, all from North America, and Thenmus aigialites Harvey from Queensland, Australia. A second species of Thenmus, $T$. augustus sp. nov., is described from the Kimberley region of Western Australia. The internal female genitalia of $M$. californicus are illustrated.
\end{abstract}

\section{INTRODUCTION}

The Menthidae is one of the smallest pseudoscorpion families and has a highly disjunct distribution with completely allopatric generic ranges in arid or supra-littoral regions of the world (Harvey and Muchmore 1990). The four species of Menthus Chamberlin occur in the deserts of southwestern U.S.A. and Mexico; the two species of Oligomenthus Beier reside in the deserts of Argentina and Chile; the sole species of Paramenthus Beier inhabits the Middle East; and the only species of Thenmus Harvey occurs above beaches in north-eastern Australia. Since the revision of the family by Harvey and Muchmore (1990), little has been subsequently published on the group. Harvey (1991b) recorded a species of Thenmus from the Kimberley region of northern Western Australia, and Harvey (1992) transferred the family, along with the Olpiidae, into a separate superfamily, the Olpioidea. Muchmore (2001) found that Atemnus gracilis Banks from Sonora, Mexico, tentatively placed in the chernetid genus Lustrochernes by Beier (1932), was a senior synonym of $M$. lindahli (Chamberlin). Most recently Ceballos (2004) presented a map showing the distribution of the family in Mexico.

The purposes of the present paper are to record additional menthid specimens recently found in museum collections, and to formally describe and name a new species from north-western Australia that was first recognised and listed by Harvey (1991b). The paper also provides distribution maps for each of the named species that were not supplied by Harvey and Muchmore (1990).

The material examined here is lodged in the American Museum of Natural History, New York (AMNH), the California Academy of Sciences, San Francisco (CAS), the University of California, Davis (UCD), and the Western Australian Museum, Perth (WAM). Terminology and mensuration mostly follows Chamberlin (1931), with the exception of the nomenclature of the pedipalps, legs and with some minor modifications to the terminology of the trichobothria (Harvey and Muchmore 1990; Harvey 1992).

The specimens were studied using one of two techniques. Temporary slide mounts were prepared by immersion of specimens in concentrated lactic acid at room temperature for several days, and mounting them on microscope slides with 10 or 12 $\mathrm{mm}$ coverslips supported by small sections of 0.25 , 0.35 or $0.50 \mathrm{~mm}$ diameter nylon fishing line. After study the specimens were returned to $75 \%$ ethanol after rinsing in water with the dissected portions placed in $12 \times 3 \mathrm{~mm}$ glass genitalia microvials (BioQuip Products, Inc.). Permanent slide mounts were prepared by removing the pedipalps, the chelicera, left leg I and left leg IV from specimens with the use of eye-scissors or small needles and clearing the body overnight with $10 \%$ potassium hydroxide at room temperature. The specimens were then washed in several rinses of water and $5 \%$ acetic acid (to neutralise the potassium hydroxide), and dehydrated through a graded ethanol series. They were then transferred to Euparal essence overnight at room temperature, prior to mounting in Euparal on microscope slides using 10 or $12 \mathrm{~mm}$ coverslips supported by small sections of $0.25,0.35$ or $0.50 \mathrm{~mm}$ diameter nylon fishing line. All specimens were studied using an Olympus $\mathrm{BH}-2$ compound microscope and illustrated with the aid of a drawing tube. Measurements were taken at the highest possible magnification using an ocular graticule.

The maps were produced with the computer program ArcView 3.2 after the relevant locality data were stored in an Access database. Coordinates were obtained from various sources, including the GeoNet Names Server (http://earth-info.nga.mil/ gns/html/) produced by the National Geospatial- 
Intelligence Agency. Recently collected specimens were usually provided with GPS coordinates taken at the collecting site.

\section{Family Menthidae Chamberlin, 1930}

\section{Genus Menthus Chamberlin, 1930}

Menthus Chamberlin, 1930: 585; Harvey and Muchmore 1990: 944-945; Harvey 1991: 261 (full synonymy).

\section{Type Species}

Minniza rossi Chamberlin, 1923, by original designation.

\section{Remarks}

Harvey and Muchmore (1990) stated that the genus Menthus lacked an unequivocal synapomorphy despite the close geographical and morphological similarities between the four known species. However, it appears that the female genitalia of Menthus spp. differ from at least one other menthid genus, Thenmus. Menthus rossi and $M$. californicus possess a large median cribriform plate covered by widely spaced acetabular plates (Figure 1), whereas $T$. aigialites (Harvey and Muchmore 1990, figure 30 ) and $T$. augustus (described below) have a relatively small plate. The female genitalia of the remaining species of the family need to be examined to establish how this feature is distributed within the family.

\section{Menthus rossi (Chamberlin, 1923)}

Minniza rossi Chamberlin, 1923: 365, plate 1 figure 5 , plate 2 figure 11, plate 3 figures $9,17$.

Menthus rossi (Chamberlin): Harvey and Muchmore, 1990: 945-948, figures 1-7; Harvey, 1991: 261 (full synonymy); Judson, 1997: 37; Ceballos, 2004: 428.

\section{New material examined}

Mexico: Chihuahua: $1 \curvearrowright, 1 \uparrow, 22$ miles N. of Parral $\left[27^{\circ} 15^{\prime} \mathrm{N}, 105^{\circ} 40^{\prime} \mathrm{W}\right], 17$ July $1956, \mathrm{~V}$. Roth and $W$. Gertsch (AMNH, S-3364.1-2, slides); $1 \delta, 1$ $q$, same data (AMNH, S-3364, spirit); 1 , same data except 19 July 1956 (AMNH, S-3370, slide); Baja California: $1 \uparrow$, Isla Salsipuedes, Gulf of California [28 $\left.44^{\prime} \mathrm{N}, 112^{\circ} 59^{\prime} \mathrm{W}\right], 21$ June 1962, R.E. Ryckman, A.E. Ryckman, C.P. Christianson (UCD, slide); 1 ơ, Bahía Concepcion $\left[26^{\circ} 39^{\prime} \mathrm{N}, 111^{\circ} 48^{\prime} \mathrm{W}\right]$, Playa El Coyote, 25 February 1987, D. Ubick (CAS).

\section{Remarks}

Chamberlin (1923, 1930) and Harvey and Muchmore (1990) recorded $M$. rossi from numerous localities in the Gulf of California and surrounding regions in north-western Mexico. The new record presented here from near Parral in the state of Chihuahua represents the first record from an inland location (Figure 8) suggesting that the species may be more widely distributed than current records indicate.

\section{Menthus mexicanus Hoff, 1945}

Menthus mexicanus Hoff, 1945: 4-7, figures 67 ; Harvey and Muchmore, 1990: 948-950, figures 8-10; Harvey, 1991: 261; Ceballos, 2004: 428.

\section{New Material Examined}

Mexico: Oaxaca: $1 \delta, 5$ miles $W$. of Tequisistlán, $16^{\circ} 25^{\prime} \mathrm{N}, 95^{\circ} 40^{\prime} \mathrm{W}, 1$ September $1964, \mathrm{~J}$. and $\mathrm{W}$. Ivie (AMNH, spirit); 5 q, 1 tritonymph, 12 miles $W$. of Tehuantepec, $16^{\circ} 20^{\prime} \mathrm{N}, 9^{\circ} 20^{\prime} \mathrm{W}, 29$ April 1963, W.J. Gertsch and $W$. Ivie (AMNH, spirit); $1 q$, same data (WAM T63294, spirit); 1 o, 1 $q, 8$ miles $W$. of Tehuantepec, $16^{\circ} 22^{\prime} \mathrm{N}, 95^{\circ} 22^{\prime} \mathrm{W}, 29$ August 1966, J. and $W$. Ivie (AMNH, spirit).

\section{Remarks}

The new material from Oaxaca listed above fits the previous descriptions of $M$. mexicanus (Hoff 1945; Harvey and Muchmore 1990). This species is known from the states of Guerrero and Oaxaca in southern Mexico (Figure 8; Harvey and Muchmore 1990).

\section{Menthus californicus Chamberlin, 1930} Figure 1

Menthus californicus Chamberlin, 1930: 587; Harvey and Muchmore 1990: 951-953, figures 14-16; Harvey 1991: 261 (full synonymy).

\section{New material examined}

U.S.A.: California: 1 o, Joshua Tree National Monument [ca. $34^{\circ} 00^{\prime} \mathrm{N}, 116^{\circ} 20^{\prime} \mathrm{W}$ ], pine-creosote bush desert, 27 April 1948, E.V. Gregg (AMNH, spirit). Nevada: Clark County: $1 \delta, 1+$, W. of Snyder Ranch [coordinates not determined], under rocks in gravel wash, 1 April 1953, L.A. Rivers (AMNH, S-2030.1-2, slides); 3 , same data (AMNH, S-2030.3-5, spirit); 3 \&, W. of Boulder Lake Boat Dock [coordinates not determined], under surface of rocks, 4 April 1953, L.A. Rivers (AMNH, S-2031.1-3, slides); 2 б, 3 \&, near Las Vegas [ca. $\left.36^{\circ} 11^{\prime} \mathrm{N}, 115^{\circ} 08^{\prime} \mathrm{W}\right]$, Covillea area, under stone, 2 April 1934, J.C. Chamberlin, E.W. Davis (CAS, JC-1065.01001-5); 1 \%, Corn Creek Desert Station $\left[36^{\circ} 26^{\prime} \mathrm{N}, 115^{\circ} 22^{\prime} \mathrm{W}\right], 8$ April 1971, S.B. Slightam (CAS).

\section{Remarks}

Menthus californicus has been previously recorded from California and Texas (Harvey and 


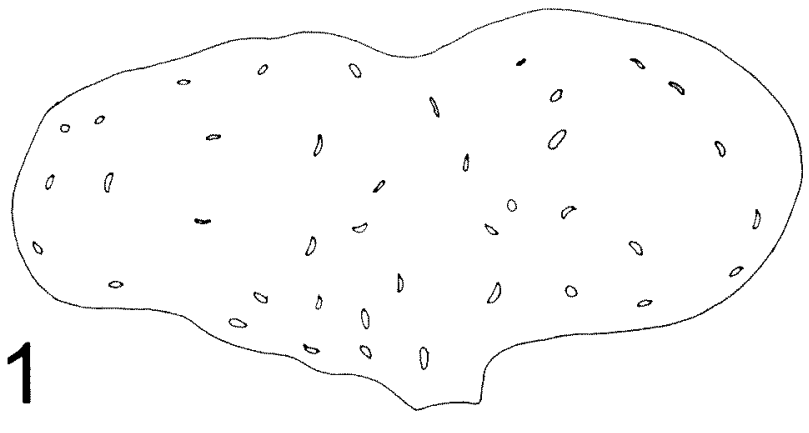

Figure 1 Menthus californicus Chamberlin, female from W. of Snyder Ranch, Nevada, U.S.A. median cribriform plate. Scale line $=0.125$ $\mathrm{mm}$.

Muchmore 1990). Several newly identified specimens from Nevada slightly extend the known distribution of this species which is widespread across south-western U.S.A. making it the most widely distributed menthid species (Figure 8).

\section{Genus Thenmus Harvey}

Thenmus Harvey, in Harvey and Muchmore 1990: 956.

\section{Type Species}

Thenmus aigialites Harvey, in Harvey and Muchmore 1990 , by original designation.

\section{Remarks}

The morphology of $T$. augustus challenges the generic diagnosis proposed by Harvey and Muchmore (1990) for Thenmus as it lacks the trichobothrial arrangement of $T$. aigialites in which trichobothrium $d$ is adjacent to ist; in $T$. augustus trichobothrium $d$ is situated adjacent to $c$. However, it possesses three features in common with $T$. aigialites that were noted in the original description of the species, but not highlighted in the generic description. The first feature is that the chelal teeth of both species are reduced to tiny, widely spaced denticles; in all other menthids the chelal teeth are well formed. The second feature is the position of trichobothrium c. In species of Menthus, Oligomenthus and Paramenthus this trichobothrium is situated antero-dorsally to trichobothrium is b, whereas in $T$. aigialites and $T$. augustus this trichobothrium is situated directly dorsal to is $b$. The third feature is the disposition of trichobothria $s b$ and $s t$; in $T$. aigialites and $T$. augustus these trichobothria are situated slightly closer to each other than to any other trichobothria, whilst in Menthus and Oligomenthus trichobothrium st is slightly closer to $t$, and in Paramenthus trichobothrium st is about midway between $t$ and $s b$. It seems clear that $T$. augustus is correctly placed in the genus Thenmus, and that further species of this rarely collected genus might be expected in other areas of tropical Australia or even Asia.

The key provided by Harvey and Muchmore (1990) must now be modified. The following generic key will assist in the identification of the four known genera:

1. Arolium twice as long as claws; flagellum of 4 blades

Arolium approximately same length as claws; flagellum of 3 blades Paramenthus Beier

2. Chelal teeth widely spaced and not numerous

Chelal teeth contiguous and numerous Menthus Chamberlin

3. Chelal teeth reduced to tiny denticles; 4 eyes present Thenmus Harvey

Chelal teeth not reduced to tiny denticles; 2 eves present Oligomenthus Beier

\section{Thenmus aigialites Harvey, 1990}

Thenmus aigialites Harvey, in Harvey and Muchmore 1990: 956-961, figures 22-39; Harvey 1992: figures 186-194.

\section{New material examined}

Australia: Queensland: 4 o, 2 tritonymphs, Shoalwater Bay, 22 $2^{\circ} 9^{\prime} 26^{\prime \prime} \mathrm{S}, 150^{\circ} 11^{\prime} 27^{\prime \prime} \mathrm{E}, 7$ August 2001, vine thicket inland of sand dune, Tullgren funnel extraction, J. Haines (WAM T44317).

\section{Remarks}

The new specimens from Shoalwater Bay were taken from a coastal vine thicket situated somewhat to the south-east of the previously known localities of this species (Harvey and Muchmore 1990).

\section{Thenmus augustus sp. nov.}

Figures $2-6$

Thenmus sp.: Harvey, 1991: 266.

\section{Material examined}

Holotype

Australia: Western Australia: $\delta, 2.4 \mathrm{~km} \mathrm{~N}$. of Augustus Point on Augustus Island, 1524'15'S, 124⒊5 'E (CALM site 26/1), 6-11 June 1988, closed forest litter, I.D. Naumann (WAM T63295).

\section{Paratypes}

Australia: Western Australia: $1 \subsetneq .4 .4 \mathrm{~km} \mathrm{SW}$ of Manning Creek, Prince Frederick Harbour, $15^{\circ} 00^{\prime} 15^{\prime \prime} \mathrm{S}, 125^{\circ} 21^{\prime} 00^{\prime \prime} \mathrm{E}$ (CALM site 8/4), 6-11 June 1988, closed forest litter, I.D. Naumann (WAM T63296); 2 tritonymphs, $5.6 \mathrm{~km} \mathrm{W.} \mathrm{of}$ 

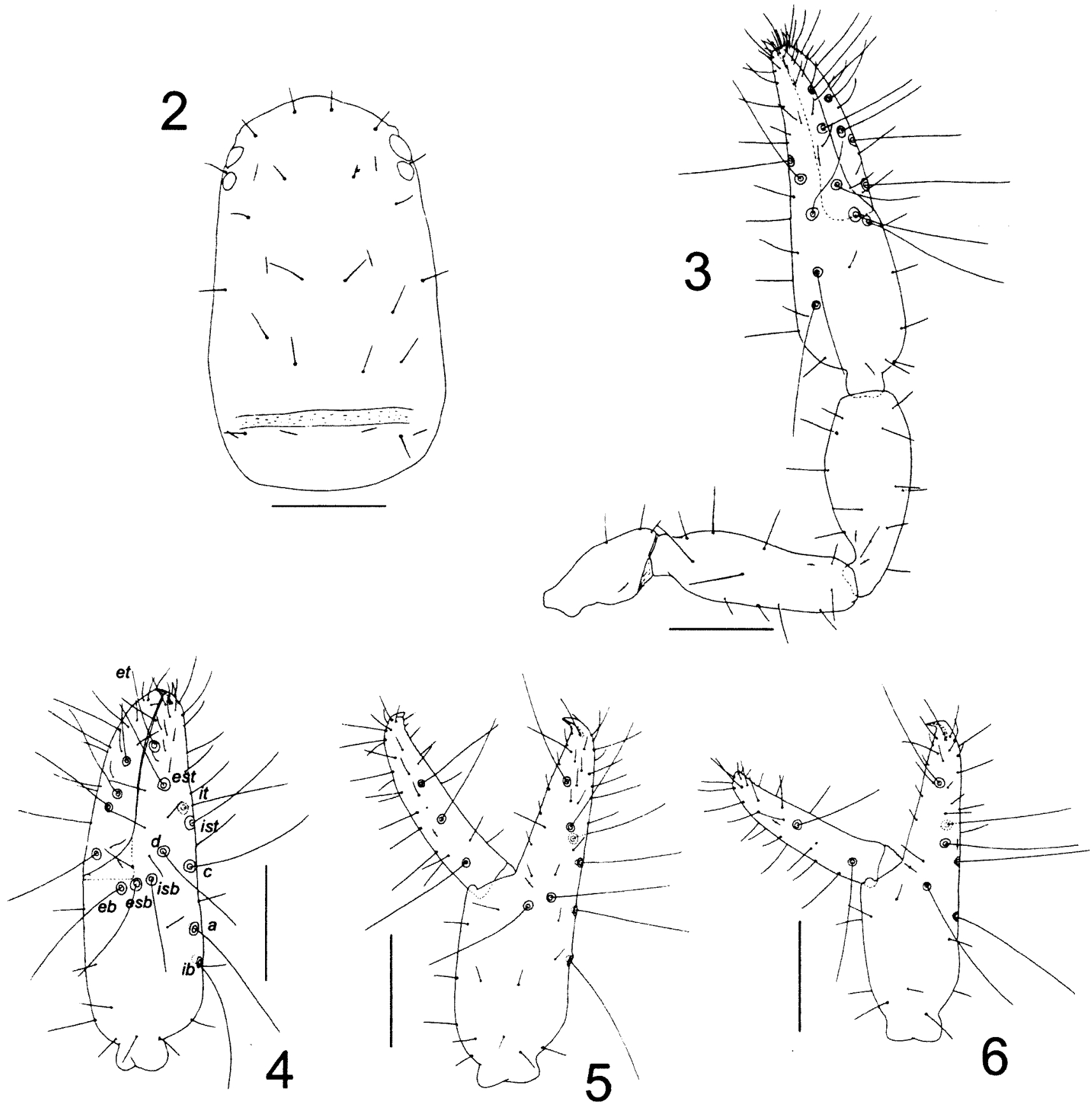

Figures 2-6 Thenmus augustus, sp. nov.: 2, carapace, paratype female; 3 , right pedipalp, dorsal, holotype male; 4 , left chela, lateral, holotype male; 5 , left chela, paratype tritonymph; 6 , left chela, paratype deutonymph. Scale lines $=0.1 \mathrm{~mm}$ (Figure 3-6), $0.2 \mathrm{~mm}$ (Figure 2).

Evelyn Island, $14^{\circ} 06^{\prime} 55^{\prime \prime} \mathrm{S}, 127^{\circ} 31^{\prime} 10^{\prime \prime} \mathrm{E}$ (CALM site 10/2), 23-31 January 1989, rainforest litter, collected by Department of Conservation and Land Management staff (WAM T63297); 3 tritonymphs, 1 deutonymph, $25.3 \mathrm{~km}$ WSW. of Mt Blythe on Charnley River, $16^{\circ} 22^{\prime} 35^{\prime \prime} \mathrm{S}$, $125^{\circ} 12^{\prime} 35^{\prime \prime}$ (CALM site 25/2), 25-31 Jan. 1989, rainforest litter, collected by Department of Conservation and Land Management staff (WAM T63298).

\section{Diagnosis}

Thenmus augustus is significantly smaller than $T$. aigialites [e.g., chela (with pedicel) 0.339 (ठ), 0.371 $(q)$ in length, compared with $0.425-0.45(\delta), 0.46-$ $0.50(\$)$ in $T$. aigialites], the carapace bears only 2 setae on the posterior margin, compared with 4 in $T$. aigialites, and trichobothrium $d$ is situated adjacent to $c$. 


\section{Description}

Adults

Body long and slender, abdomen not much wider than carapace width. Colour with sclerotized portions generally very pale, pedipalps and anterior portion of carapace red-brown.

Chelicera: with 5 setae on hand, all setae acuminate; movable finger with 1 subdistal seta; subterminal tooth of movable finger not bifurcate and not enlarged; galea of $\delta$ and $q$ deeply bifurcate with 2 long rami; flagellum of 4 aspinose blades; serrula exterior with $16(\delta), 17$ (q) blades; lamina exterior present, very thin.

Pedipalp (Figure 3): all pedipalpal segments completely smooth; setae sparse, very long and acicular; trochanter without tubercles; trochanter $2.14(\delta), 2.16(q)$, femur $3.15(\delta), 2.92(q)$, patella $2.43(8), 2.34(q)$, chela (with pedicel) 3.29 (ठ), 2.99 ( $q$ ), chela (without pedicel) $3.15(\delta), 2.81(q)$, hand long and cylindrical, $1.37(\delta), 1.29(\$)$ times longer than broad, movable finger $1.33(0), 1.22$ (9) times longer than hand. Femur with 2 long tactile seta. Patella with three lvrifissures situated dorsally near pedicel. Fixed chelal finger with 11 trichobothria, movable chelal finger with 4 trichobothria (Figure 4): $e b$, esb and isb situated in straight line at base of finger; $d$ situated slightly in advance of $c$, it and ist situated submedially; est and et situated subdistally; $i b$ and a on dorsal margin of hand; ca. 4 microsetae (chemosensory setae) present on fixed finger distal to et, trichobothria of movable finger with $s b$ and st situated closer to each other than to others; microsetae (chemosensory setae) not present on movable finger. Venom apparatus only present in fixed chelal finger, venom ducts very short, terminating in nodus ramosus almost immediately. Chelal teeth small, widely spaced; fixed finger with ca. 14 (ठ) teeth; movable finger with ca. 10 (d) teeth; accessory teeth absent. Exterior and interior chelal condyles small and rounded.

Cephalothorax: Carapace (Figure 2) 1.58 (3), 1.71 (q) times longer than broad; sub-rectangular; with 2 pairs of flat, corneate eyes situated near anterior margin of carapace, posterior pair slightly smaller than anterior pair; with 22 (b), 21 (क) setae, including 4 near anterior margin and 2 near posterior margin; $q$ with single sub-basal furrow, $\delta$ without furrow; with 4 pairs of lyrifissures, 1 pair near eyes, 1 pair medially and 2 pairs near posterior margin. Manducatory process with 1 long distal, 1 long sub-distal and very small internal, sub-oral seta; remainder of maxilla with 6 setae. Chaetotaxy of coxae I-IV: $6: 5: 4: 4(6), 7: 7: 5: 5(q)$. Coxal area narrow, nearly parallel-sided; junction between coxae II and III with specialised articulation joint typical of family (Chamberlin 1931; Harver and Muchmore 1990)

Abdomen: Pleural membrane longitudinally striate. Tergites and sternites without medial suture. Tergal chaetotaxy: $8,6: 6: 4: 6: 6: 6: 6: 6: 6:$ 1T1T1T1T1: TT1TT: 2; \&, 6:6:5:6:6:6:6:6:6: 1T1T1T1T1: TT1TT: 2 ; uniseriate; all setae acicular. Sternal chaetotaxy: o, $7:(0) 6[1+1](0):(2) 4(2): 4: 6: 6$ : 6: 6: T1 T2T1T: 1T1T1: 2 ; $, 5:(0) 9(0):(2) 5(2): 6: 6: 6$ : 6: 6: T2T2T2T: 1T1T1: 2 ; setae uniseriate and acuminate; glandular setae absent; anus not surrounded by sternite $X I$.

Genitalia: Male with no perceptible differences from $T$. aigialites: anterior apodemes small and recurved; lateral apodemes consisting of 2 separate tubes, fused distally and basally; lateral apodemes apparently with anterior arm; dorsal apodemes posteriorly placed; ejaculatory canal atrium large; dorsal anterior gland apparently absent. Female: with paired lateral cribriform plates and single small median cribriform plate; spermathecae absent.

Legs: junction between femora and patellae I and II not broad, and is apparently mobile; femur I longer than patella 1; femur + patella of 2.72 (q) times longer than broad; femora I and II with 1 perpendicular lyrifissure situated sub-distally; tibiae III and IV without tactile seta; metatarsi III and IV with moderately long sub-basal tactile seta; subterminal tarsal setae arcuate and acute; arolium much longer than claws, not divided.

\section{Dimensions (mm)}

Male holotype: Body length 1.23. Pedipalps: trochanter $0.131 / 0.061$, femur $0.208 / 0.066$, patella $0.202 / 0.083$, chela (with pedicel) $0.339 / 0.103$, chela (without pedicel) 0.324 , hand length 0.141 , movable finger length 0.187 . Carapace $0.320 / 0.203$; anterior eye diameter 0.020 , posterior eye diameter 0.013 .

Female paratype: Body length 1.57. Pedipalps: trochanter $0.138 / 0.064$, femur $0.216 / 0.074$, patella $0.218 / 0.093$, chela (with pedicel) $0.371 / 0.124$, chela (without pedicel) 0.349 , hand length 0.160 , movable finger length 0.195 . Carapace $0.339 / 0.198$; anterior eve diameter 0.020 , posterior eye diameter 0.018 . Leg IV: femur + patella $0.234 / 0.086$, tibia $0.160 / 0.048$, metatarsus $0.056 / 0.029$, tarsus $0.077 / 0.026$.

\section{Tritonymphs}

Morphology generally as in adults. Colour with all sclerotized portions generally very pale.

Chelicera: with 5 setae on hand, all setae acuminate; movable finger with 1 subdistal seta galea deeply bifurcate with 2 long rami; flagellum of 4 blades; lamina exterior present, very thin

Pedipalp: all pedipalpal segments completely smooth; setae sparse, very long and acicular trochanter without tubercles; trochanter 2.16, femur 3.03, patella 2.43, chela (with pedicel) 3.30, chela (without pedicel) 3.04, hand 1.51 times longer than broad, movable finger 1.17 times longer than hand Femur with 2 long tactile setae. Patella with three lyrifissures situated dorsally near pedicel. Fixed 

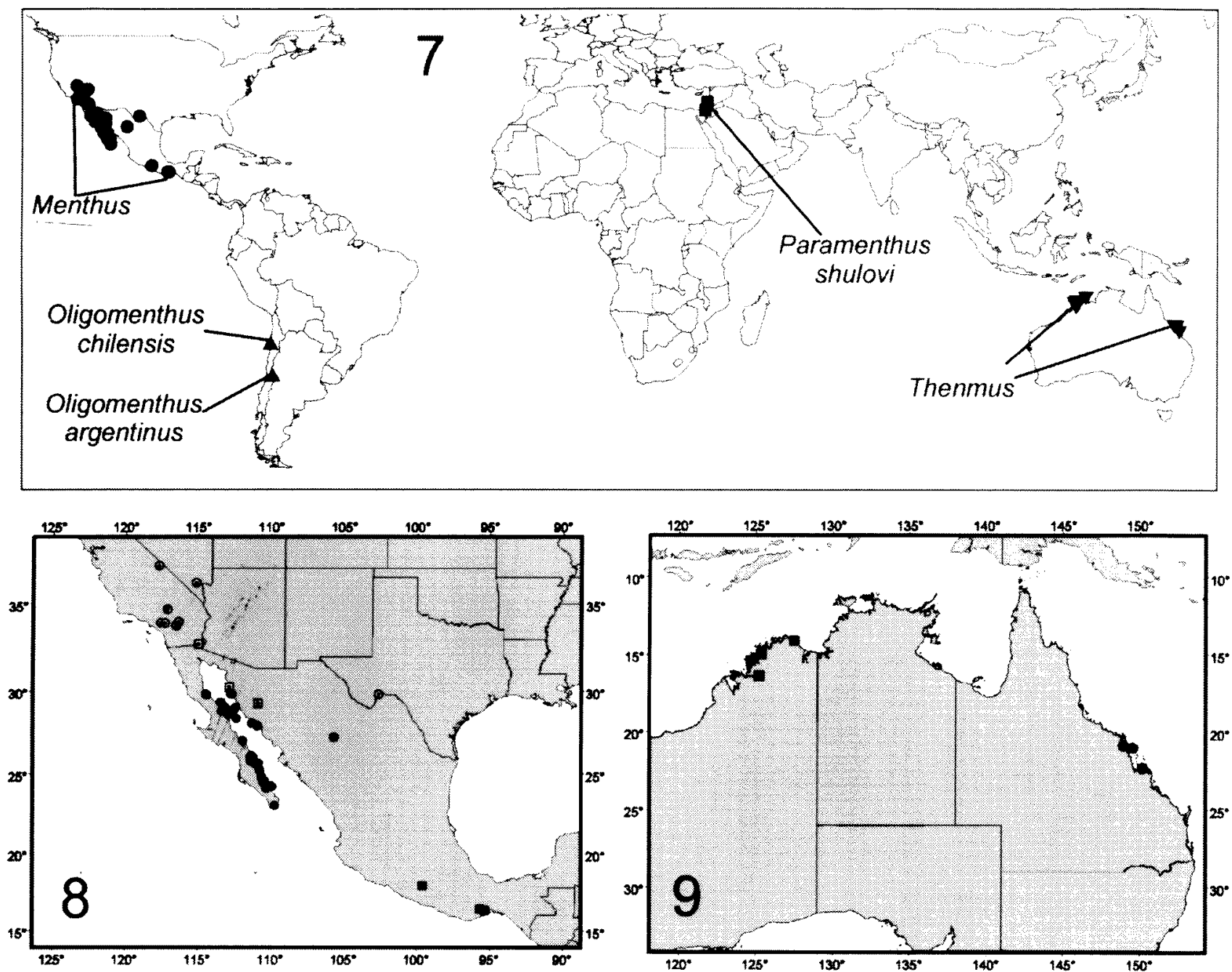

Figures 7-9 Maps showing recorded distributions of Menthidae: 7, all records; 8, Menthus rossi $(\bullet)$, M. mexicanus ( $M$. californicus $(\odot)$ and $M$. gracilis $(\square) ; 9$, Thenmus aigialites $(\bullet)$ and $T$. augustus $(\square)$

chelal finger with 8 trichobothria, movable chelal finger with 3 trichobothria (Figure 5): is $b, c, d$ and $s b$ absent; $e b$ and $e s b$ situated at base of finger; est, it and ist situated submedially; et situated subdistally; $i b$ and $a$ on dorsal margin of hand. Venom apparatus only present in fixed chelal finger, venom ducts very short, terminating in nodus ramosus almost immediately. Chelal teeth small, widely spaced; fixed finger with ca. 9 teeth; movable finger with 5 teeth, all situated distally.

Cephalothorax: carapace 1.49 times longer than broad; sub-rectangular; with 2 pairs of flat, corneate eyes situated near anterior margin of carapace; with 20 setae, including 4 near anterior margin and 4 near posterior margin. Coxal area with junction between coxae II and III with specialised articulation joint typical of family.

Abdomen: Pleural membrane longitudinally striate. Tergites and sternites without medial suture. Glandular setae absent; anus not surrounded by sternite XI.
Legs: femur I longer than patella I; tibiae III and IV without tactile seta; metatarsi III and IV with moderately long sub-basal tactile seta; metatarsi and tarsi not fused; arolium much longer than claws, not divided.

\section{Dimensions (mm)}

Tritonymph paratype (WAM T63298): Body length 1.28. Pedipalps: trochanter $0.125 / 0.058$, femur $0.200 / 0.066$, patella $0.192 / 0.079$, chela (with pedicel) $0.327 / 0.099$, chela (without pedicel) 0.301 , hand length 0.149 , movable finger length 0.175 . Carapace $0.319 / 0.214$.

\section{Deutonymphs}

Morphology generally as in adults. Colour with all sclerotized portions generally very pale.

Chelicera: with 5 setae on hand, all setae acuminate; movable finger with 1 subdistal seta; galea deeply bifurcate with 2 long rami; flagellum of 4 blades; lamina exterior present, very thin. 
Pedipalp: all pedipalpal segments completely smooth; setae sparse, very long and acicular; trochanter without tubercles; trochanter 2.02, femur 2.77, patella 2.48, chela (with pedicel) 3.16 , chela (without pedicel) 3.03 , hand 1.72 times longer than broad, movable finger 1.31 times longer than hand. Femur with 2 long tactile setae. Patella with three lyrifissures situated dorsally near pedicel. Fixed chelal finger with 6 trichobothria, movable chelal finger with 2 trichobothria (Figure 6): esb, isb, a, $c$, $d, s b$ and st absent; $e b$ situated at base of finger; est, it and ist situated submedially; et situated subdistally; $i b$ on dorsal margin of hand. Venom apparatus only present in fixed chelal finger, venom ducts very short, terminating in nodus ramosus almost immediately. Chelal teeth small, widely spaced; fixed finger with 5 teeth; movable finger with 4 teeth, all situated distally.

Cephalothorax: carapace 1.30 times longer than broad; sub-rectangular; with 2 pairs of flat, corneate eyes situated near anterior margin of carapace; with 18 setae, including 4 near anterior margin and 2 near posterior margin. Coxal area with junction between coxae II and III with specialised articulation joint typical of family.

Abdomen: Pleural membrane longitudinally striate. Tergites and sternites without medial suture. Glandular setae absent; anus not surrounded by sternite XI.

Legs: femur I longer than patella I; tibiae III and IV without tactile seta; metatarsi III and IV with moderately long sub-basal tactile seta; metatarsi and tarsi not fused; arolium much longer than claws, not divided.

\section{Dimensions (mm)}

Deutonymph paratype (WAM T63298): Body length 1.13. Pedipalps: trochanter $0.109 / 0.054$, femur $0.166 / 0.060$, patella $0.166 / 0.067$, chela (with pedicel) $0.294 / 0.093$, chela (without pedicel) 0.282 , hand length 0.122 , movable finger length 0.160 . Carapace $0.291 / 0.224$

\section{Remarks}

This small species has been found in three localities in the Kimberley region of Western Australia (Figure 9) where it occurs in rainforest litter.

\section{Etymology}

The specific epithet is a noun in apposition taken from the type locality.

\section{ACKNOWLEDGEMENTS}

The specimens utilised in this study were kindly provided by Norman McKenzie (Department of
Conservation and Land Management, Perth), Norman Platnick (AMNH), Charles Griswold and Vince Lee (CAS), Steve Heydon (UCD) and Heather Proctor (formerly Griffith University). I am very grateful to two anonymous referees for their constructive comments on the manuscript.

\section{REFERENCES}

Beier, M. (1932). Pseudoscorpionidea II. Subord. C. Cheliferinea. Tierreich 58: i-xxi, 1-294.

Ceballos, A. (2004). Pseudoscorpionida. In J.L. Bousquets, J.J. Morrone, O.Y. Ordónez and I.V. Fernández (eds), Biodiversidad, taxonomía y biogeografía de Artrópodos de México: hacia una sintesis de su conocimiento, vol. 4: 417-429. Facultad de Ciencias, UNAM, México, D.F.

Chamberlin, J.C. (1923). New and little known pseudoscorpions, principally from the islands and adjacent shores of the Gulf of California. Proceedings of the California Academy of Sciences (4) 12: 353-387.

Chamberlin, J.C. (1930). A synoptic classification of the false scorpions or chela-spinners, with a report on a cosmopolitan collection of the same. Part II. The Diplosphyronida (Arachnida-Chelonethida). Annals and Magazine of Natural History (10) 5: 1-48, 585620 .

Chamberlin, J.C. (1931). The arachnid order Chelonethida. Stanford University Publications, Biological Sciences 7(1): 1-284.

Harvey, M.S. (1991a). Catalogue of the Pseudoscorpionida. Manchester University Press, Manchester.

Harvey, M.S. (1991b). The Pseudoscorpionida and Schizomida of the Kimberley rainforests. In N.L. McKenzie, R.B. Johnston and P.G. Kendrick (eds), Kimberley Rainforests, pp. 265-268. Surrey Beatty \& Sons, Chipping Norton.

Harvey, M.S. (1992). The phylogeny and systematics of the Pseudoscorpionida (Chelicerata: Arachnida) Invertebrate Taxonomy 6: 1373-1435.

Harvey, M.S. and Muchmore, W.B. (1990). The systematics of the family Menthidae (Pseudoscorpionida). Invertebrate Taxonomy 3: 941964.

Hoff, C.C. (1945). New neotropical Diplosphyronida (Chelonethida). American Museum Novitates 1288: 117.

Judson, M.L.I. (1997). Catalogue of the pseudoscorpion types (Arachnida: Chelonethi) in the Natural History Museum, London. Occasional Papers on Systematic Entomology 11: 1-54.

Muchmore, W.B. (2001). On the identity of Atemnus gracilis Banks (Pseudoscorpiones: Menthidae). Entomological New's 112: 230-231.

Manuscript recowed 15 August 2005; accepted 7 February 2006 